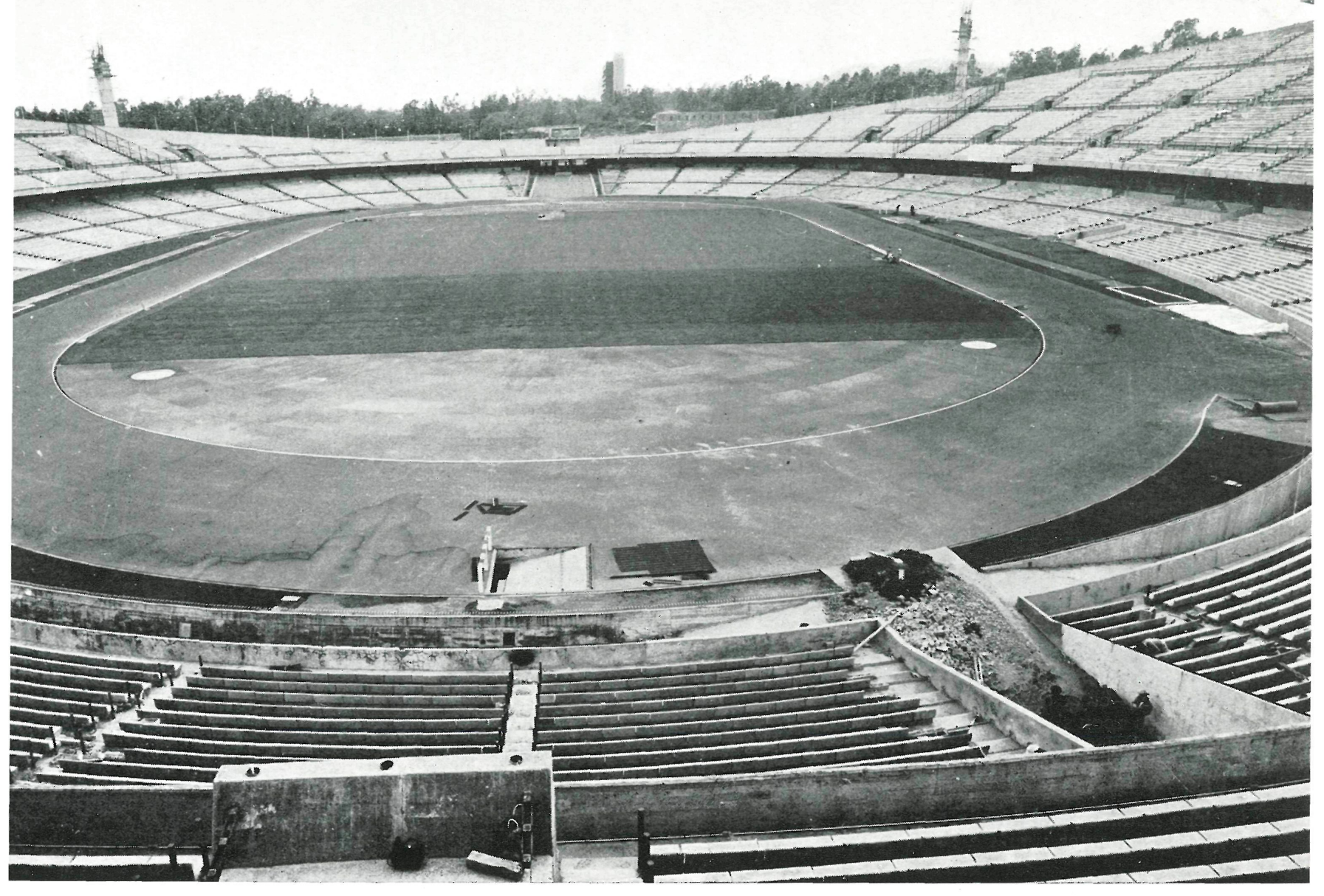

\title{
estadio olámpiè de la Ciudad Universitaria
}

A. PEREZ PALACIOS, J. BRAVO y R. SALINAS MORO, arquitectos

\section{sinopsis}

El Estadio - ya existente - fue sometido a las obras y adaptaciones precisas para que cumpliese los requisitos olímpicos, y sirviese como sede de las ceremo. nias de apertura y clausura de los XIX Juegos Olímpicos. Se encuentra situado a $3,8 \mathrm{~km}$ d
Olímpica y a $15,6 \mathrm{~km}$ de la Plaza Mayor.

Las principales adaptaciones fueron las siguientes: dotarle de áreas para los servicios de prensa; ampliacion de las gradas altas; ejecución de nuevas esreforma de los asientos; y reconstrucción del campo y de la pista de atletismo, que se recubrió con una capa de material plástico.

Su planta tiene la forma de ovoide, inscrita en una circunferencia de $125 \mathrm{~m}$ de radio, con el eje longidel campo.

El aforo total es de 80.000 localidades.

2. Jardines del Pedregal de San Angel.-3. Estacionamiento de taxis. -4. Transportes colectivos.-5. Estacionamiento de invitados especiales y prensa.-7. Plaza de acceso.-8. Transportes colectivos.-9. Entrada de servicio.-10. Caseta Foto Finish.-11. Tribuna general. - 12. Prensa. - 13. Invitados especiales. deportistas.-17. Paso desnivel.-18. Reposo de atletas.-19. Servicio médico-20. Oficinas para deportistas.-21. Terminal de tranvías.-22. Estacionamiento de atletas.-24. Pista y campo.-25. Avenida de los Insurgentes.-27. Paseo de las Facultades.

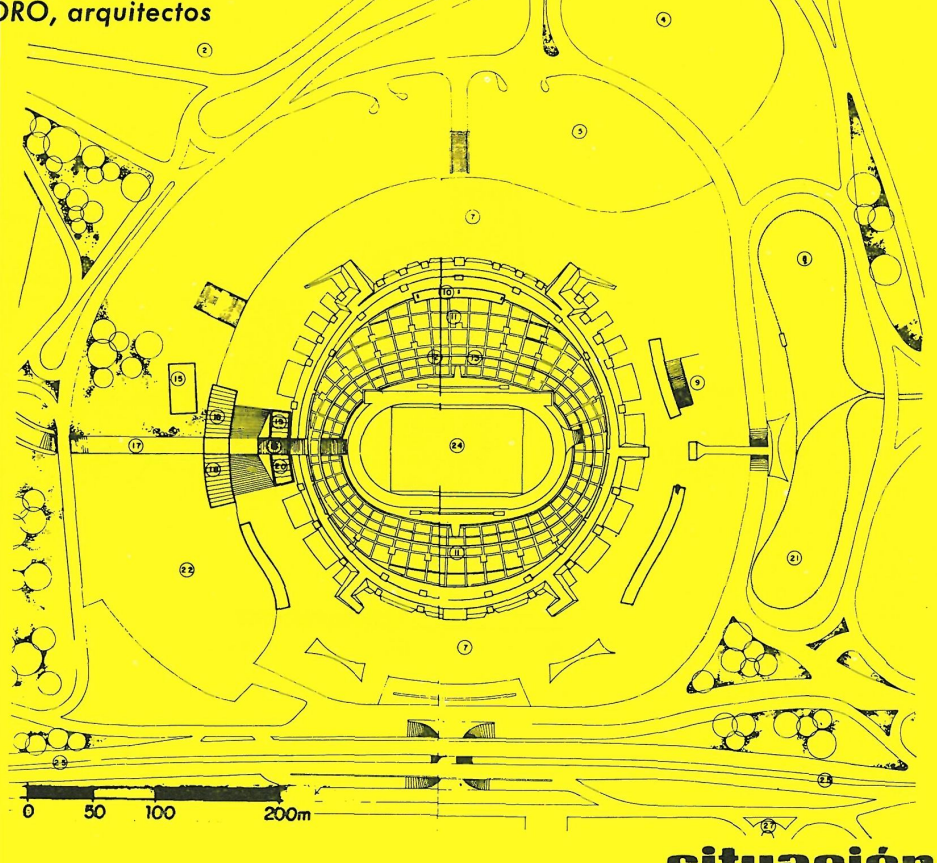

sifuación 

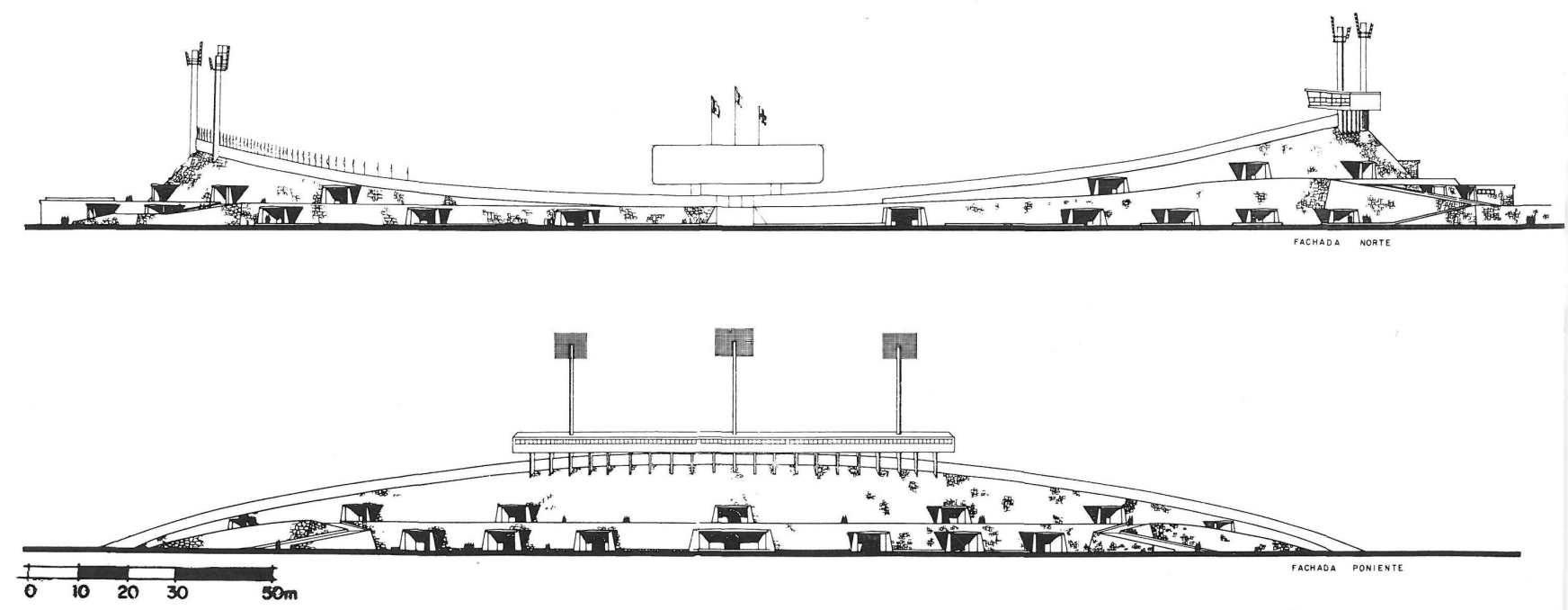

alzados

Con la finalidad de convertirlo en la Instalación más importante de los XIX Juegos Olímpicos, en el Estadio existente -cuya construcción data de 1952- se realizaron las obras y adaptaciones precisas para que cumpliera todos los requisitos olímpicos y, además, se mejoró la pista y campo con el fin de que sirviera para la celebración de las competiciones de atletismo, así como de todos los actos solemnes.

El aforo total es de 80.000 localidades.

Dicho Estadio está situado en la zona noroeste de la Ciudad Universitaria, con su eje mayor paralelo a la Avenida Insurgentes y al eje de composición principal que corresponde al Rectorado. Recordemos, a este respecto,

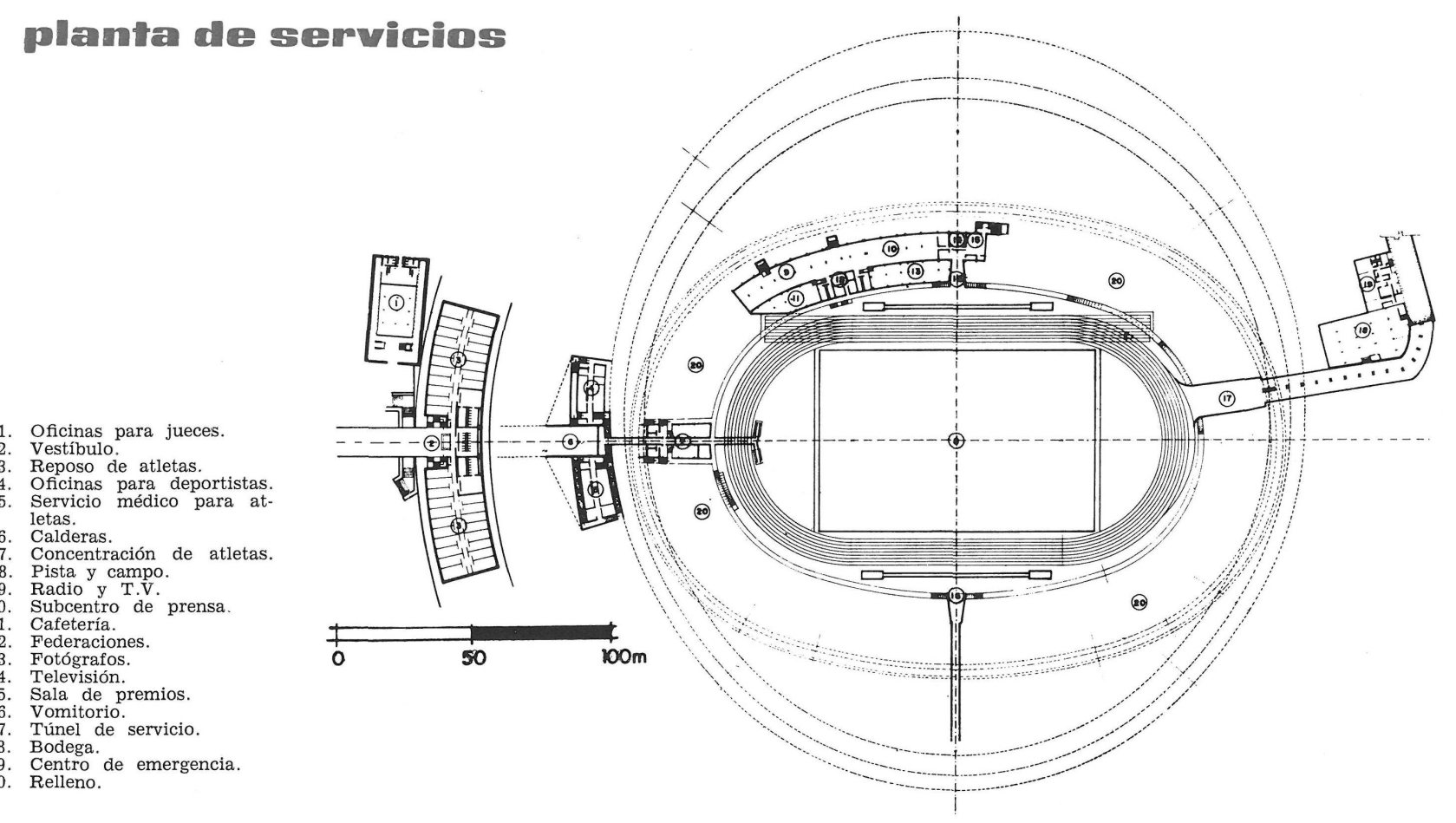




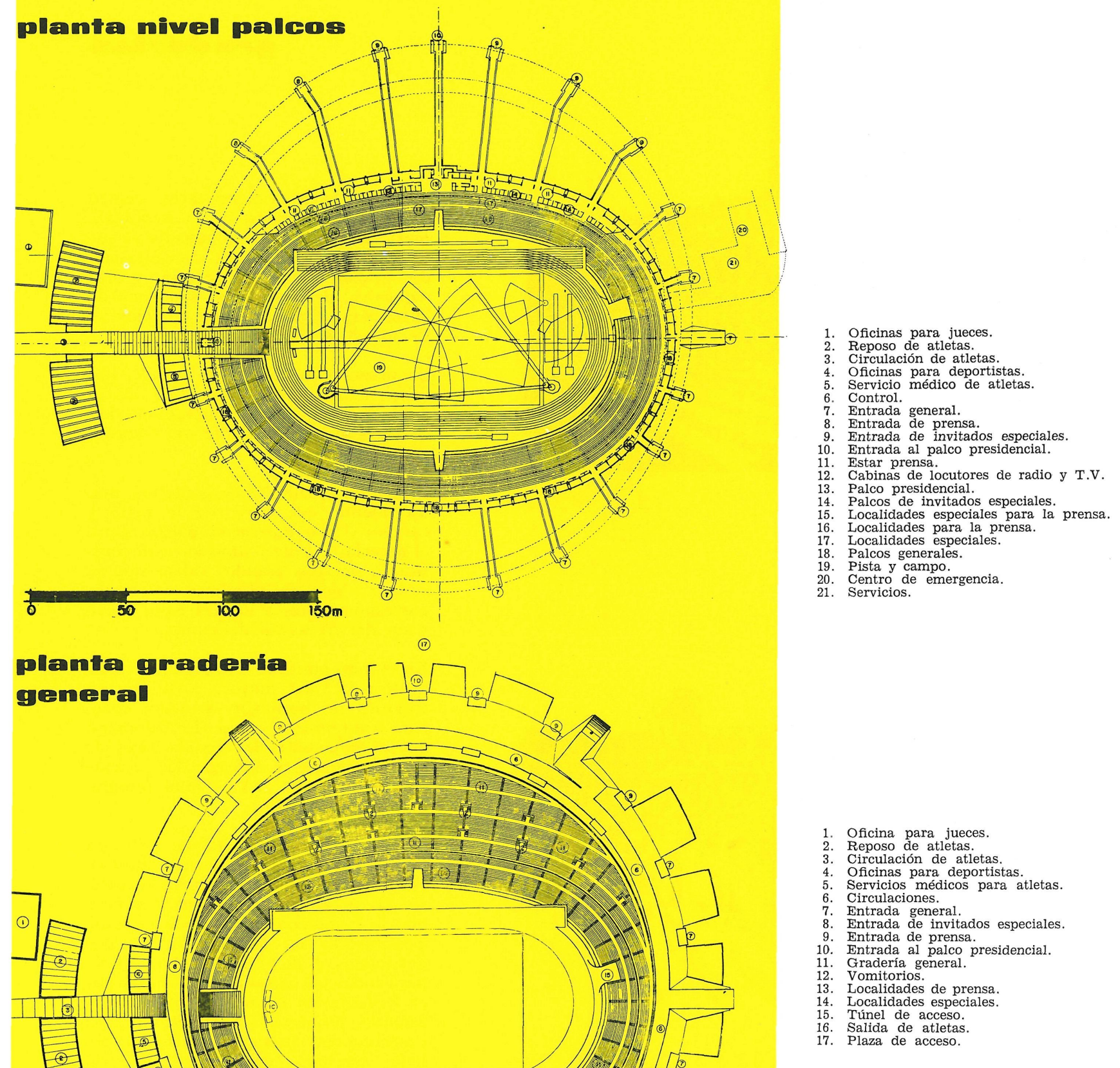




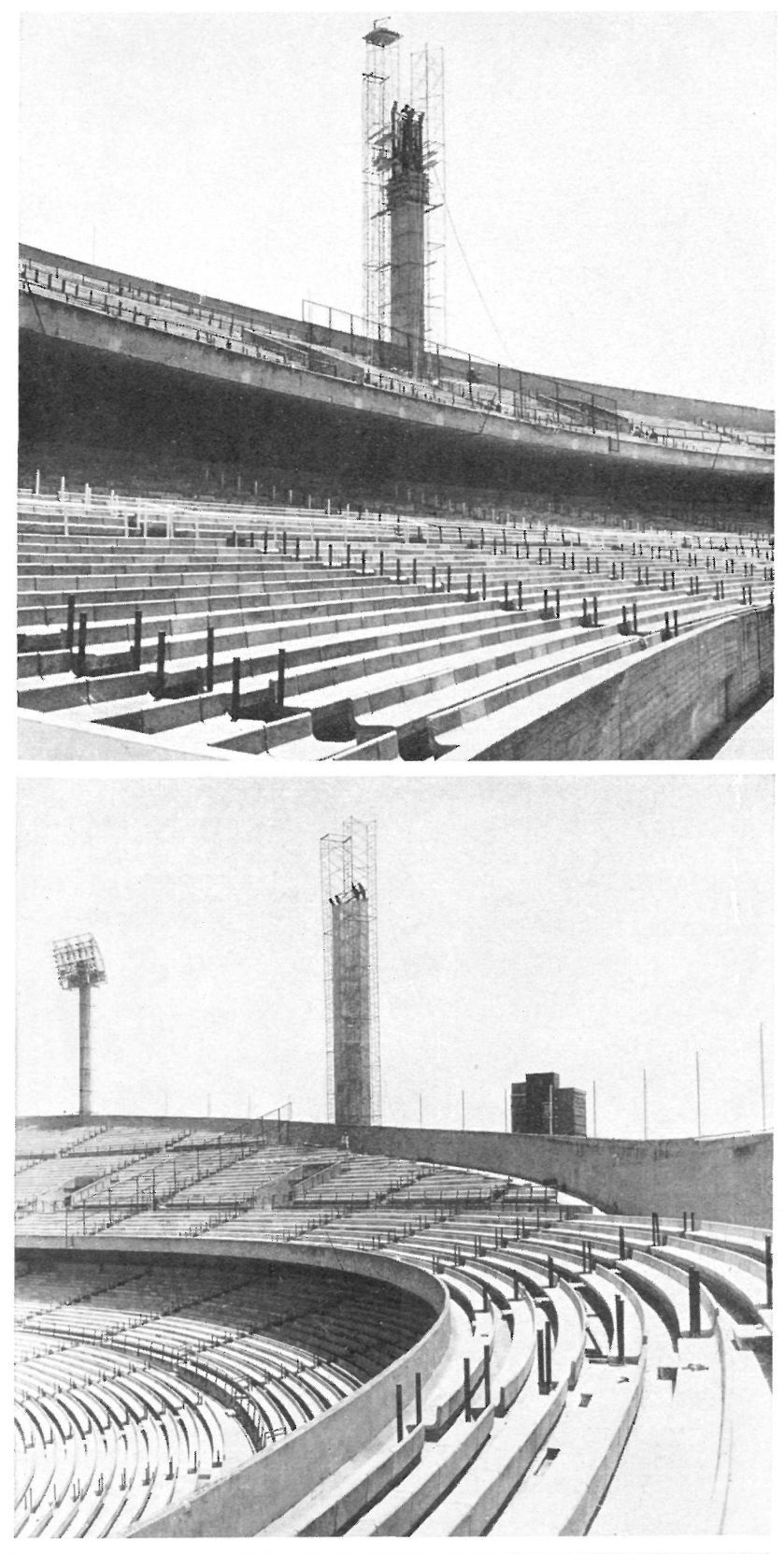

\section{graderias}

que la Ciudad Universitaria, centro principal de estudios de la República mexicana, se encuentra ubicada al sur de la Ciudad de México; y cuenta con dos grandes zonas, una escolar y otra deportiva, destacando en cada una de ellas, respectivamente, dos edificios: el Rectorado y el Estadio Olímpico.

Su planta tiene forma de ovoide, inscrito en una circunferencia de $125 \mathrm{~m}$ de radio, con el eje longitudinal desfasado $8 \mathrm{~m}$ hacia poniente con respecto al del campo.

Consta de dos niveles de graderías; uno ascendente, que parte de la pista y campo; y otro, que forma balcón sobre el anterior. El nivel superior está constituido por dos grandes valvas que se juntan y ligan en las partes más bajas, correspondientes a los extremos norte y sur del eje mayor del campo.

En el lado poniente, y elevada con respecto a la valva mayor, existe una estructura de hormigón armado, conocida comúnmente como «El Palomar», que domina todas las instalaciones de pista y campo, y alberga: las casetas de prensa, radio, T.V. y final fotográfico (Photo-Finish).

Cuenta con palco de honor, que está provisto de todos los servicios necesarios adecuados a su categoría e, incluso, en el antepalco hay un ascensor que lo comunica con la zona de estacionamiento de automóviles; palcos destinados a la prensa, radio y T.V., para todas las categorías señaladas por el Reglamento Olímpico; gradas, con asientos numerados y generales para espectadores; ambigús; cuartel de policía; servicios médicos de urgencia para el público; áreas de concesiones; servicios sanitarios; etc.

Para la organización de las competiciones olímpicas fueron acondicionadas: un área de oficina y trabajo para jueces, con capacidad simultánea para 550 personas; oficinas para la Federación Internacional de Atletismo y su correspondiente personal; oficinas para la Dirección Técnica de Actos, en donde han sido organizadas áreas para cada uno de los que formaban parte del programa de atletismo.

Los atletas disponían de los siguientes servicios: zona de calentamiento con pista y campo; zona de concentración

16

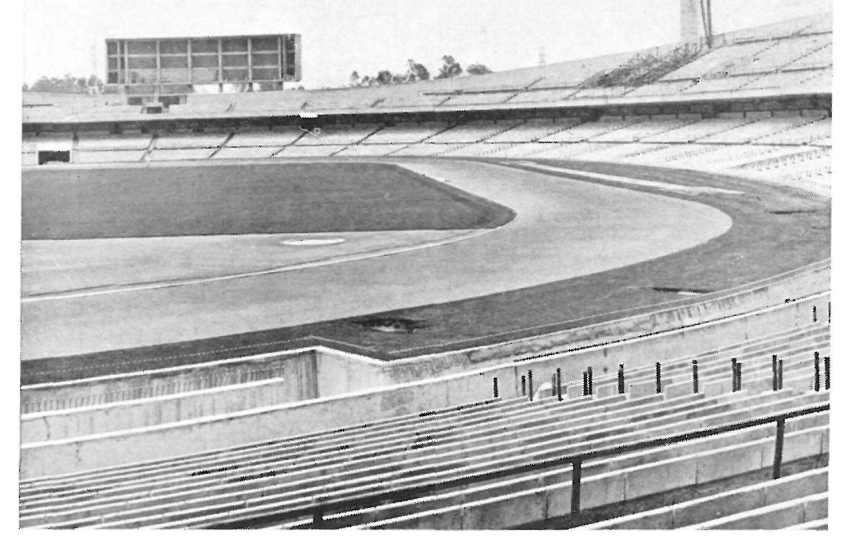



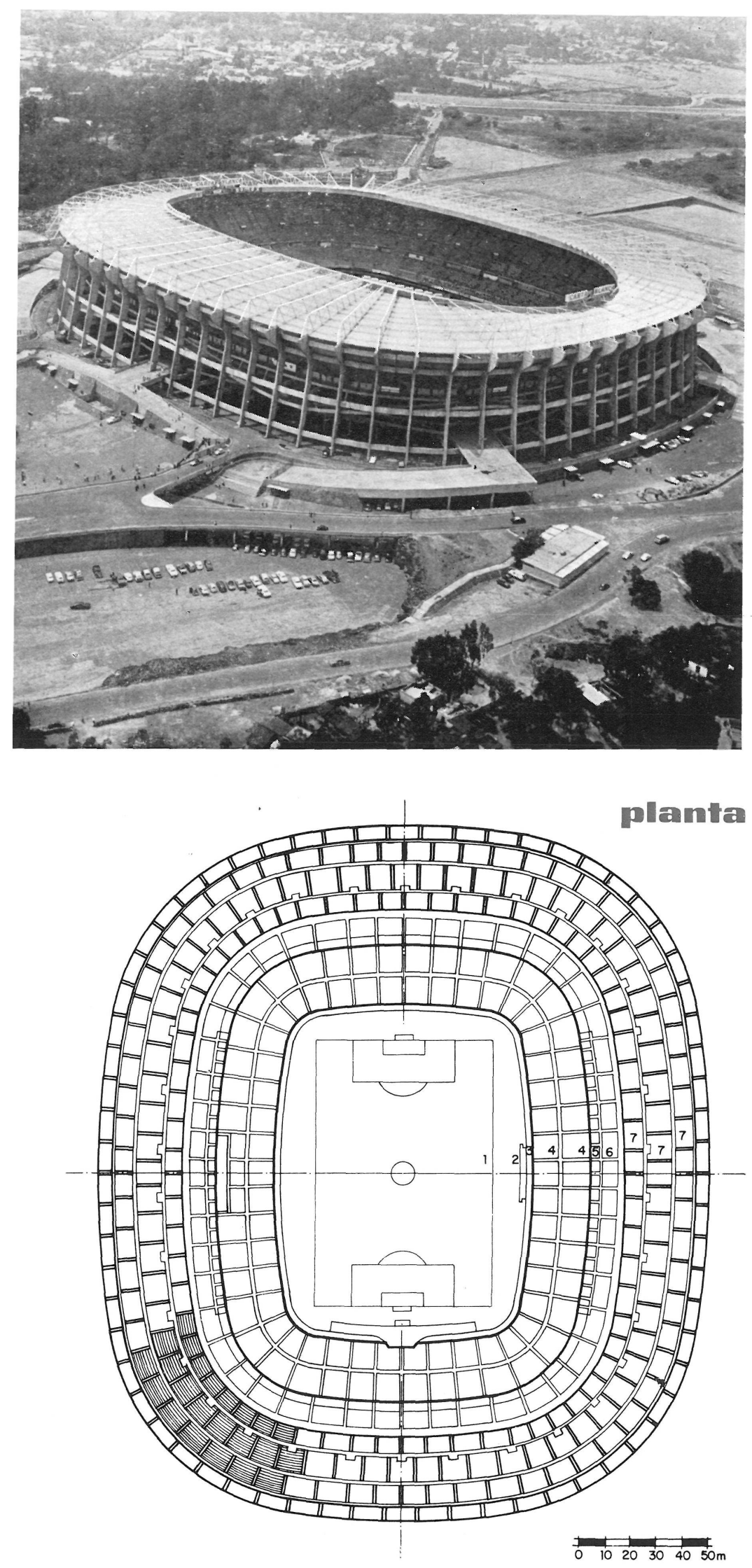

1. Cancha.-2. Banca de asistentes.-3. Foso.-4. Especial numerado.-5. Plateas altas.-6. Preferente numerado.-7. Gradería general.

\section{estadio azteca}

de atletas, con cuartos de espera, servicios sanitarios, de control, de costura; servicios médicos; oficinas; zona de reposo con 38 vestuarios para 20 personas cada uno; baños y sanitarios independientes para hombres y mujeres; $\mathrm{y}$ oficinas para jueces.

Por lo que respecta a los Servicios de Información, la prensa contó además: de asientos en gradas provistos de pupitre; de un antepalco provisto de «barras» para alimentos y bebidas; servicios sanitarios; áreas de dispersión; y bajo el nivel de graderías, pero comunicados directamente con un área de trabajo de prensa de $440 \mathrm{~m}^{2}$ : laboratorio fotográfico; zona de entrevistas; cafetería y aseos; mesa común de información; un estacionamiento privado; etc.

Específicamente, radio y T.V. dispusieron de cabinas especiales para comentaristas, y de varias estaciones para cámaras de televisión; igualmente en cabinas especiales estuvieron situadas dos cámaras de cine y fotógrafos de prensa.

Señalaremos, como características constructivas de las obras realizadas, que las cantidades de materiales empleados fueron: $2.583 \mathrm{~m}^{3}$ de hormigón; 3 a $7 \mathrm{t}$ de hierro en armaduras; $3.121 \mathrm{~m}^{3}$ de piedra; $3.100 \mathrm{~m}^{3}$ de hormigón asfáltico; y $2.200 \mathrm{~m}$ de tubos de cemento, en drenajes.

En definitiva, las principales adaptaciones realizadas en las instalaciones ya existentes fueron: áreas apropiadas para servicios de prensa; zonas de reposo y de calentamiento para los atletas; ampliación de «El Palomar»; ejecución de nuevas estructuras para el tablero marcador e iluminación; reforma de los asientos; pero de todo ello merece una mención especial la reconstrucción total del campo y de la pista de atletismo, recubierta con una capa de material plástico inerte adecuado para «todo tiempo».

Dicho acabado de la pista, que fue previamente aprobado por la Federación Internacional de Atletismo, es de color rojo, siendo la primera vez que se usa en unos juegos olímpicos. Lleva una base de grava cementada natural, con una capa superior de hormigón asfáltico $\mathrm{y}$, finalmente, el material plástico vertido in situ. 

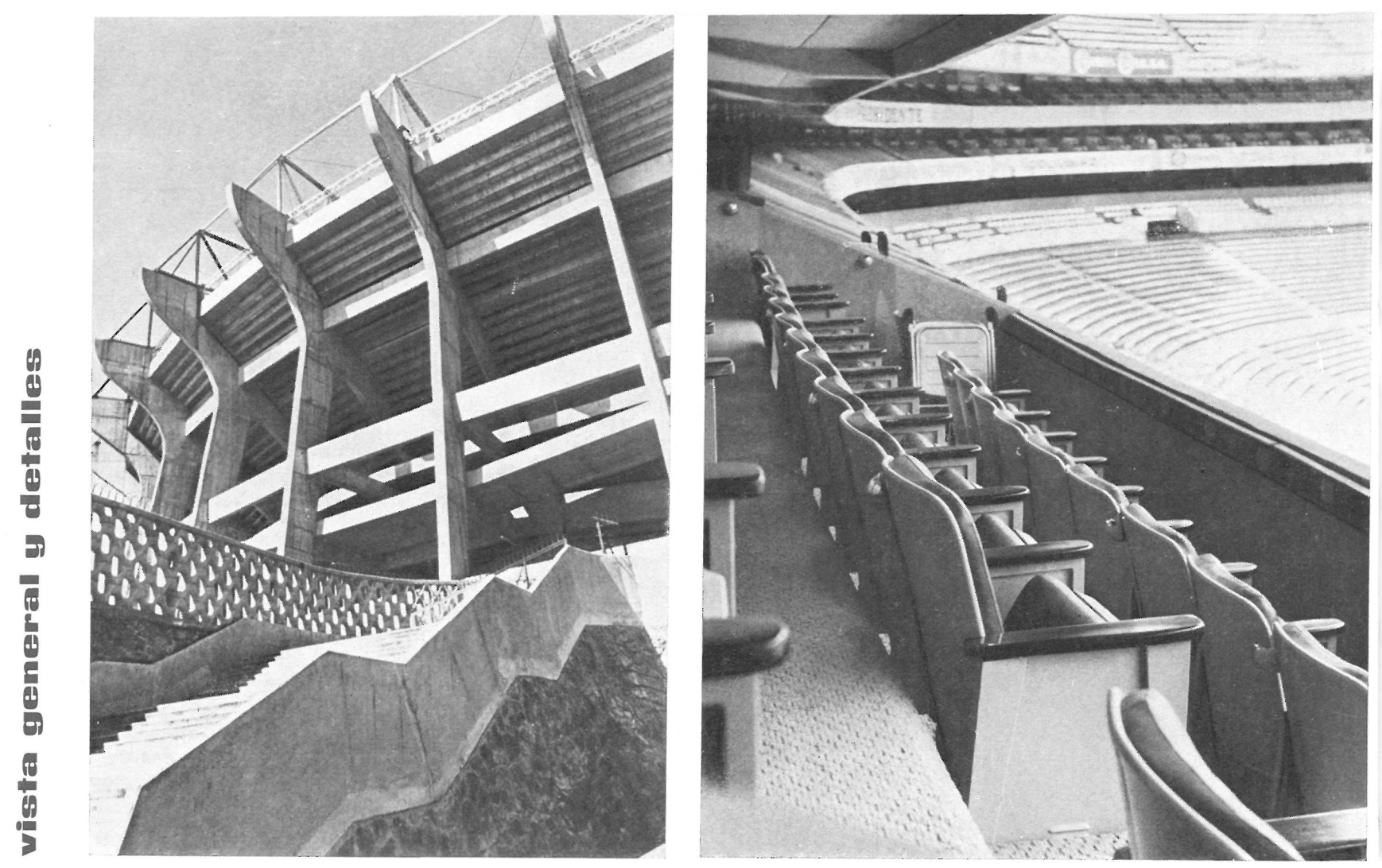

Finalmente, este Estadio Olímpico, distante $3,8 \mathrm{~km}$ de la Villa Olímpica y 15,6 km de la Plaza Mayor, constituyó la instalación más importante de los XIX Juegos Olímpicos, y sirvió como sede de las ceremonias de apertura y clausura de los mismos.

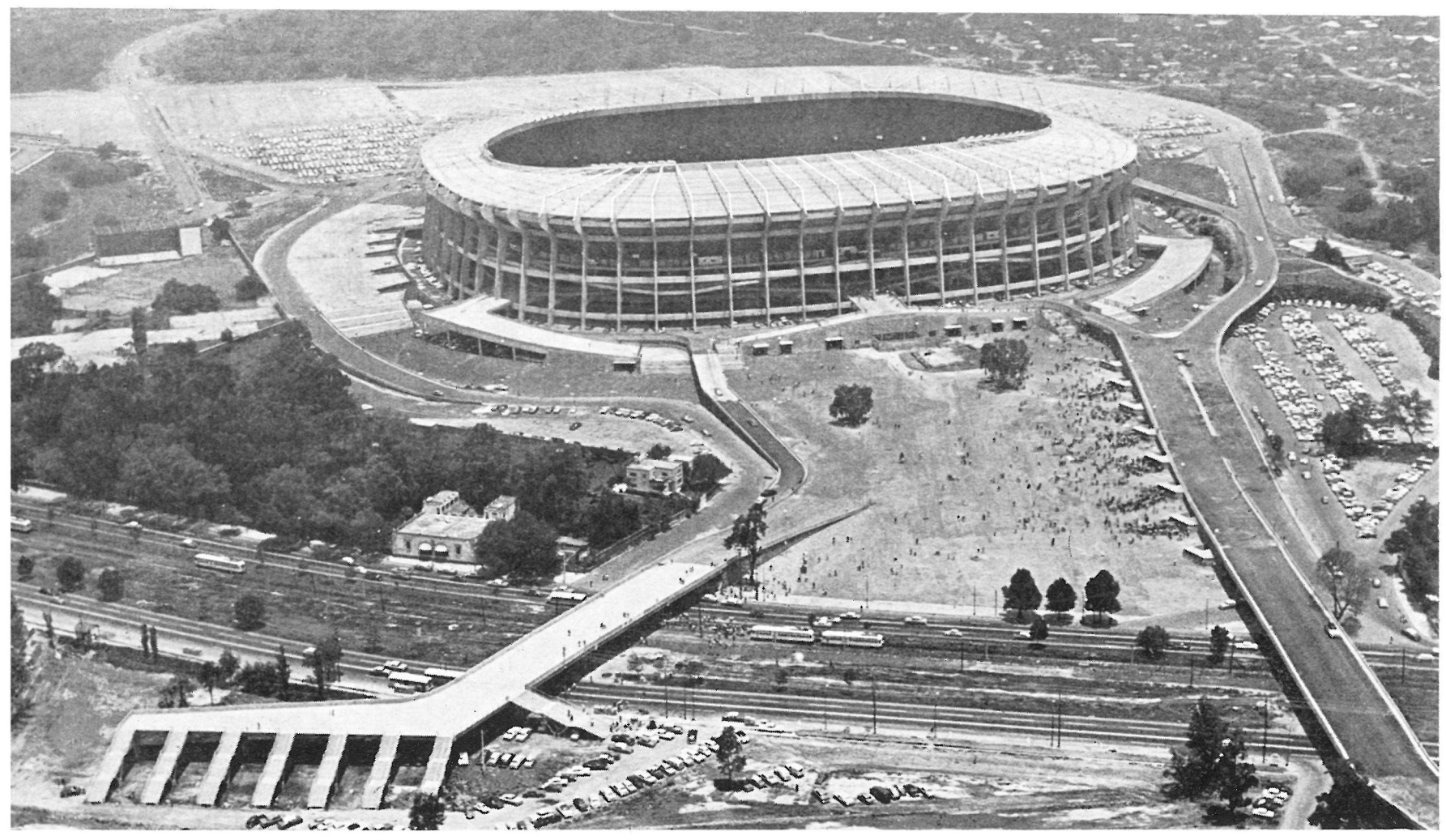

